\title{
AGGREGATION PHEROMONES AND HOST KAIROMONES OF WEST INDIAN SUGARCANE WEEVIL, Metamasius hemipterus sericeus
}

\section{A. L. PEREZ, ${ }^{1,7}$ Y. CAMPOS, ${ }^{2}$ C. M. CHINCHILLA, ${ }^{2}$}

A. C. OEHLSCHLAGER, ${ }^{1, *}$ G. GRIES, ${ }^{3}$ R. GRIES, ${ }^{3}$

R. M. GIBLIN-DAVIS, ${ }^{4}$ G. CASTRILLO ${ }^{2}$ J. E. PEÑA, ${ }^{5}$ R. E. DUNCAN, ${ }^{4}$ L. M. GONZALEZ, ${ }^{6}$ H. D. PIERCE, JR., R. McDONALD, ${ }^{1}$ and R. ANDRADE ${ }^{6}$

\author{
'Department of Chemistry \\ Simon Fraser University \\ Burnaby, British Columbia, Canada VSA IS6 \\ ${ }^{2}$ Palm Research Program, ASD de Costa Rica \\ Apdo. 30-1000 San José, Costa Rica \\ ${ }^{3}$ Centre for Pest Management \\ Department of Biological Sciences \\ Simon Fraser Universiny \\ Burnaby, British Columbia, Canada V5A IS6 \\ ${ }^{4}$ University of Florida, Institute of Food and Agricultural Sciences \\ Fort Lauderdale Research and Education Center \\ Fort Lauderdale, Florida \\ ${ }^{5}$ University of Florida, Institute of Food and Agricultural Sciences \\ Tropical Research and Education Center \\ Homestead, Florida \\ ${ }^{6}$ ChemTica Internacional, $S$. A. \\ Apdo. 159-2150, San José, Costa Rica
}

(Received September 21, 1995; accepted November 18, 1996)

\begin{abstract}
Coupled gas chromatographic-electroantennographic detection (GC-EAD) analyses and coupled GC-mass spectrometry (MS) of volatiles produced by male and female West Indian sugarcane weevils (WISW), Metamasius hemipterus sericeus (Oliv.), revealed eight male specific, EAD-active compounds: 3-pentanol (1), 2-methyl-4-heptanol (2), 2-methyl-4-octanol (3),
\end{abstract}

* To whom correspondence should be addressed.

'Current address: Department of Chemistry, University of Costa Rica, 2060 San Pedro, San José, Costa Rica. 
4-methyl-5-nonanol (4), and the corresponding ketones. In field experiments in Florida, alcohols 1-4 in combination with sugarcane were most attractive, whereas addition of the ketones or replacement of alcohols with ketones significantly reduced attraction. In Costa Rica field experiments testing alcohols 1-4 singly and in all binary, ternary, and quaternary combinations revealed 4 in combination with 2 was the major aggregation pheromone, equally attracting male and female WISW. Stereoisomeric 4 and $(4 S, 5 S)-4$, the only isomer produced by WISW, were equally attractive. Addition of $4 S-, 4 R-$ or $( \pm)-2$ to $(4 S, 5 S)-4$ significantly enhanced attraction. Sugarcane stalks in combination with 2 plus 4 (ratio of $1: 8$ ) were highly synergistic, whereas EAD-active sugarcane volatiles ethyl acetate, ethyl propionate, or ethyl butyrate only moderately increased attractiveness of the pheromone lure.

Key Words-Coleoptera, Curculionidae, Metamasius hemipterus sericeus, aggregation pheromones, pheromone chirality, $(4 S, 5 S)-4$-methyl-5-nonanol, 2-methyl-4-heptanol, sugarcane, ethyl acetate, ethyl propionate, ethyl butyrate.

\section{INTRODUCTION}

The West Indian sugarcane weevil (WISW), Metamasius hemipterus sericeus (Oliv.) (Coleoptera: Curculionidae), is a pest of banana, pineapple, palms, and sugarcane in Central and South America, the Caribbean and Africa (Vaurie, 1966). In the mid-1980s the WISW was introduced into Florida, where it has become a significant pest of ornamental palms and sugarcane (Giblin-Davis et al., 1994a). The WISW has recently been implicated in Colombia as a possible vector of the nematode, Bursaphelenchus cocophilus, responsible for red ring disease in oil palm (Calvache et al., 1995).

Attraction of Metamasius spp. to sugarcane (Teran, 1968; Raigosa, 1974; Woodruff and Baranowski, 1985) is used in Central America to infect field populations with entomopathogens (Carballo and Arias de Lopez, 1994). Volatiles emitted by several host plants and by male WISW attract male and female weevils (Giblin-Davis et al., 1994a). We report the identification of and field attraction to male-produced aggregation pheromones and to host volatiles.

\section{METHODS AND MATERIALS}

\section{Volatile Collection}

Adult weevils of mixed age, sex, and mating status were collected in a banana plantation $7 \mathrm{~km}$ west of Homestead, Dade County, Florida. Thirty-eight male and 38 female weevils were aerated separately for four days (12L:12D photoperiod) in modified Nalgene (5311) desiccators $(32.9 \mathrm{~cm}$ high $\times 25.1 \mathrm{~cm}$ ID) containing water-moistened Kimwipe papers. A mechanical pump was used 
to draw charcoal-filtered air ( 2 liters/min) through the chamber and insect-produced volatiles were trapped on Porapak Q $(10 \mathrm{~g})$ (Oehlschlager et al., 1988). Using another desiccator, freshly harvested sugarcane stalk $(1 \mathrm{~kg}$, cut in $5 \mathrm{~cm}$ sections) was aerated for $48 \mathrm{hr}$. Volatiles from all aerations were eluted separately from Porapak $\mathrm{Q}$ with pentane $(\sim 175 \mathrm{ml})$ and concentrated to $\sim 5 \mathrm{ml}$ by slow distillation of the solvent through a Dufton column.

\section{Instrumental Methods}

Porapak Q-trapped volatiles were analyzed by gas chromatographic-electroantennographic detection (GC-EAD) (Am et al., 1975) employing a HewlettPackard (HP) 5890 gas chromatograph equipped with a fused silica column coated with SP-1000 (30 m $\times 0.25 \mathrm{~mm}$ ID; Supelco, Inc., Bellafonte, Pennsylvania). Antennal responses were amplified using a custom-built amplifier with a passive low-pass filter and a cutoff frequency of $10 \mathrm{kHz}$. A HP 5985B coupled GC-mass spectrometer (GC-MS) fitted with the same column, a DB-5-coated (30 $\mathrm{m} \times 0.25 \mathrm{~mm}$ ID), or a Cyclodex-B-coated fused silica column $(30 \mathrm{~m} \times$ $0.25 \mathrm{~mm}$ ID; both from J \& W Scientific, Folsom, California) were used for GC-MS analyses of extracts employing both electron impact (EI, $70 \mathrm{eV}$ ) and chemical ionization (CI) using isobutane as the proton source in full-scan modes. Diastereoisomeric derivatives of 4-methyl-5-nonanol (4) were analyzed on a 5890 Hewlett-Packard gas chromatograph using a DB-1 coated fused silica column $(15 \mathrm{~m} \times 0.25 \mathrm{~mm} \mathrm{ID} ; \mathrm{J} \& \mathrm{~W}$ Scientific $)$.

\section{Chemicals and Syntheses}

Racemic 4-methyl-5-nonanol (4) was prepared ( $80 \%$ yield, $95 \%$ purity, bp $90^{\circ} \mathrm{C}$ at $10 \mathrm{~mm} \mathrm{Hg}$ ) as in previous work (Perez et al., 1996). Stereoisomers of 4-methyl-5-nonanol $[(4 S, 5 S)-4,98 \%$ ee; $(4 R, 5 R)-4,97 \%$ ee] were available in this laboratory from previous work (Perez et al., 1996). Racemic 2-methyl-4heptanol (2) was prepared by reaction of propyl magnesium bromide with isovaleraldehyde in ether solution at room temperature. Standard work-up yielded $2,89 \%$ yield, $96 \%$ purity, bp $70^{\circ} \mathrm{C}$ at $15 \mathrm{~mm} \mathrm{Hg}$. Racemic 2-methyl-4-octanol (3) was synthesized in a fashion similar to that used for the preparation of 2 but using butyl magnesium bromide $\left(87 \%\right.$ yield, $95 \%$ purity, bp $73^{\circ} \mathrm{C}$ for $13 \mathrm{~mm}$ $\mathrm{Hg}$ ). 3-Pentanol (4) and 3-pentanone (5) were purchased (Aldrich Chemical Company, Milwaukee, Wisconsin). 2-Methyl-4-heptanone (6, 87\% yield, 95\% purity; bp $60^{\circ} \mathrm{C}$ at $15 \mathrm{~mm} \mathrm{Hg}$ ) and 2-methyl-4-octanone $(7,86 \%$ yield, $95 \%$ purity; bp $67^{\circ} \mathrm{C}$ at $13 \mathrm{~mm} \mathrm{Hg}$ ) were obtained by oxidation of the corresponding alcohols with Jones' reagent (Fieser and Fieser, 1967), 4-Methyl-5-nonanone $\left(8,85 \%\right.$ yield, $95 \%$ purity, bp $80^{\circ} \mathrm{C}$ at $11 \mathrm{~mm} \mathrm{Hg}$ ) was prepared as in previous work (Perez et al., 1996). 
(E)-6-Methyl-2-hepten-4-ol (9). This was prepared as previously described by reaction of isobutyl magnesium bromide and crotonaldehyde in diethyl ether (Oehlschlager et al., 1992). Purification by fractional distillation at reduced pressure $\left(61^{\circ} \mathrm{C}\right.$ at $\left.12 \mathrm{~mm} \mathrm{Hg}\right)$ yielded $80 \%$ of $( \pm)-9$.

(R,E)-6-Methyl-2-hepten-4-ol [(RE)-9] (Figure 1). Titanium(IV) isopropoxide $(2.28 \mathrm{ml}, 7.4 \mathrm{mmol})$ in dry $\mathrm{CH}_{2} \mathrm{Cl}_{2}(80 \mathrm{ml})$ was mixed under argon with $0.5 \mathrm{~g}$ of $3 \mathrm{~A}$ powdered, activated molecular sieves. After cooling to $-78^{\circ} \mathrm{C}$, diethyl $(2 R, 3 R)$-tartrate [L-(+)-DET, $1.56 \mathrm{ml}, 9.12 \mathrm{mmol}$ ] was added via syringe followed by addition of $( \pm)-9(1.84 \mathrm{~g}, 14.4 \mathrm{mmol})$ and $15 \mathrm{mmol}$ of decane as internal standard. The mixture was stirred $15 \mathrm{~min}$ prior to dropwise addition of precooled $6.6 \mathrm{M}$ anhyd. tert-butyl hydroperoxide in $\mathrm{CH}_{2} \mathrm{Cl}_{2}(4.25 \mathrm{ml}, 28 \mathrm{mmol})$. After the reaction warmed to $-20^{\circ} \mathrm{C}$, it was stirred at this temperature for 0.5-1 hr. The reaction was monitored by GC and was stopped at $\sim 50 \%$ conversion. Optical purity of $(R E)-9$ was determined by gas chromatography of the corresponding acetyllactate derivatives (Slessor et al., 1985) on a DB-1 column. Aqueous work-up followed by column chromatography $\left(2: 8 \mathrm{Et}_{2} \mathrm{O}\right.$-pentane) gave (RE)-9 $(0.75 \mathrm{~g}, 81 \%$ yield based on $50 \%$ conversion, $97 \%$ ee) as a colorless liquid. 'H NMR $\left(\mathrm{CDCl}_{3}, \mathrm{ppm}\right): 0.89(3 \mathrm{H}, \mathrm{d}, J=8.1 \mathrm{~Hz}), 0.91(3 \mathrm{H}, \mathrm{d}, J=$ $8.1 \mathrm{~Hz}), 1.36(1 \mathrm{H}, \mathrm{m}), 1.44(2 \mathrm{H}, \mathrm{m}), 1.70(3 \mathrm{H}, \mathrm{d}, J=8.1 \mathrm{~Hz}), 1.90(1 \mathrm{H}$, brs), $4.08(1 \mathrm{H}, \mathrm{q}), 5.44(1 \mathrm{H}, \mathrm{dd}, J=8.1,16.2 \mathrm{~Hz}), 5.65(1 \mathrm{H}, \mathrm{dq}, J=8.1$, $16.2 \mathrm{~Hz}) ;{ }^{13} \mathrm{C} \mathrm{NMR}\left(\mathrm{CDCl}_{3}, \mathrm{ppm}\right): 137.76,126.44,71.33,46.94,28.23$, $24.57,22.92,22.50,22.25,17.60$. This process has been reported previously in lower enantiopreference (Oehlschlager et al., 1992).

(S,E)-6-Methyl-2-hepten-4-ol [(SE)-9] (Figure 1). This enantiomer was prepared $(0.86 \mathrm{~g}, 93 \%$ yield based on $50 \%$ conversion, $95 \%$ ee) following the above procedure using diethyl $(2 S, 3 S)$-tartrate [D-(-)-DET] as the epoxidation catalyst. ${ }^{1} \mathrm{H}$ and ${ }^{13} \mathrm{C}$ NMR spectra were identical to those given for $(R E)-9$.

(S)-2-Methyl-4-heptanol [(S)-2] (Figure 1). A modification of Brown's method (Fieser and Fieser, 1967) was used to reduce (RE)-9. A 50-ml filtration

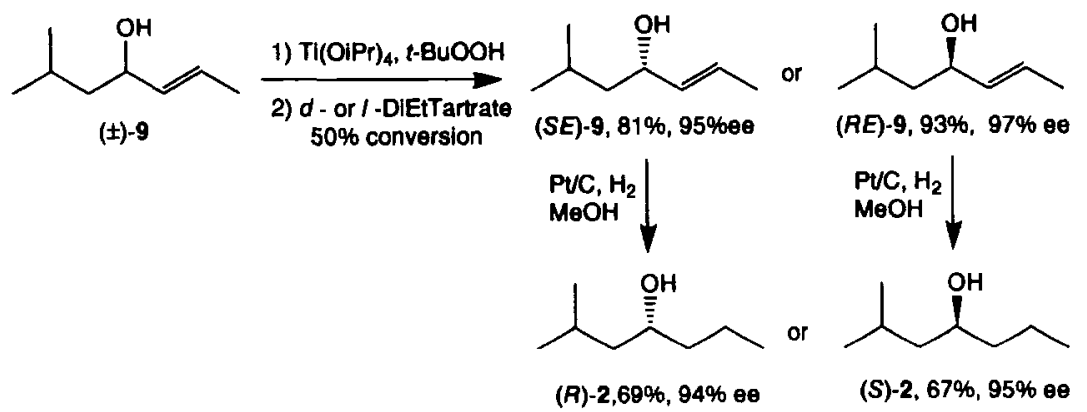

Fig. 1. Scheme for synthesis of $(S)$ - and $(R)$-2-methyl-4-heptanol [(S)- and $(R)-2]$. 
flask was charged with a solution of $(R E)-3(0.73 \mathrm{~g}, 5.7 \mathrm{mmol})$ in dry methanol $(20 \mathrm{ml})$ and 0.05 eq. of $5 \% \mathrm{Pt} / \mathrm{C}$. The flask was capped with a septum and a rubber bulb was secured with wire to the side arm. After flushing with nitrogen gas, $\mathrm{H}_{2}$ was introduced until the rubber bulb inflated. The suspension was stirred at room temperature until deflation of the balloon ceased. GC analysis (DB- $I$ ) of aliquots withdrawn periodically indicated completion of the reaction after 3 hr. The system was purged with $\mathrm{N}_{2}$ and the mixture filtered, diluted with water, and extracted $(3 \times 10 \mathrm{ml})$ with $\mathrm{Et}_{2} \mathrm{O}$. The extract was dried over anhyd. $\mathrm{MgSO}_{4}$ and the solvent removed in vacuo to afford a light yellow oil. The residue was distilled at reduced pressure $\left(70^{\circ} \mathrm{C}\right.$ at $\left.15 \mathrm{~mm} \mathrm{Hg}\right)$ to give $(S)-2$ as a colorless liquid $(0.51 \mathrm{~g}, 67 \%$ yield, $95 \%$ ee $)$. Optical purity was determined by gas chromatographic analysis of the acetyllactates and acetates on a Cyclodex $B$ column. $[\alpha]_{\mathrm{D}}^{20}=+14.3^{\circ}\left(c=2.230, \mathrm{Et}_{2} \mathrm{O}\right) ;{ }^{1} \mathrm{H} \mathrm{NMR}\left(\mathrm{CDCl}_{3}, \mathrm{ppm}\right): 0.89$ $(3 \mathrm{H}, \mathrm{d}, J=7.5 \mathrm{~Hz}), 0.92(3 \mathrm{H}, \mathrm{d}, J=7.5 \mathrm{~Hz}), 0.94(3 \mathrm{H}, \mathrm{t}, J=7.5 \mathrm{~Hz})$, $1.24(1 \mathrm{H}, \mathrm{m}), 1.38(6 \mathrm{H}, \mathrm{m}), 1.76(1 \mathrm{H}, \mathrm{m}), 3.77(1 \mathrm{H}, \mathrm{m}) ;{ }^{13} \mathrm{C} \mathrm{NMR}\left(\mathrm{CDCl}_{3}\right.$, ppm): $69.69,46.86,40.26,24.62,23.28,22.03,18.68,13.97$; El-MS $m / z$ (relative intensity): $112\left(\mathrm{M}^{+}-18,17\right), 87\left(\mathrm{M}^{+}-\mathrm{C}_{3} \mathrm{H}_{7}, 42\right)$. Anal. calcd. for $\mathrm{C}_{8} \mathrm{H}_{18} \mathrm{O}: \mathrm{C}, 73.78 ; \mathrm{H}, 13.93$. Found: $\mathrm{C}, 73.68 ; \mathrm{H}, 13.85$.

(R)-2-Methyl-4-heptanol [(R)-2]. (Figure 1). A procedure as described above for the preparation of $(S)-2$ was used to prepare $(R)-2:[\alpha]_{\mathrm{D}}^{20}=-10.20^{\circ}$ $\left(c=2.280, \mathrm{Et}_{2} \mathrm{O}\right) ; 0.60 \mathrm{~g}, 69 \%$ yield, $94 \%$ ee. Anal. calcd. for $\mathrm{C}_{8} \mathrm{H}_{18} \mathrm{O}: \mathrm{C}$, 73.78; $\mathrm{H}, 13.93$. Found: $\mathrm{C}, 73.63 ; \mathrm{H}, 13.81$.

\section{Field Experiments}

Field tests of candidate semiochemicals were conducted in a 2-year-old banana plantation near Homestead, Florida, and in commercial oil palm plantations near Coto, Costa Rica. Experiments with 7-10 replicates each employed pitfall traps (Giblin-Davis et al., 1994b) or Dipel traps (Oehlschlager et al., 1993) set up in complete randomized blocks with treatments and blocks $20 \mathrm{~m}$

apart. Pitfall traps used in pheromone experiments contained $2-3 \mathrm{~cm}$ of soapy (3\% by weight of Alkonox) or, equally effective, insecticide-laced ( $3 \mathrm{~g} /$ liter of Sevin 80) water to retain captured weevils. Traps were buried in the shade with their openings $2-3 \mathrm{~cm}$ above the soil surface. Dipel traps used in kairomone experiments were hung at chest height from palms. Attractants were suspended from the lid, and insecticide-treated food or water covered the trap bottom. Racemic candidate pheromones 1-8 were dispensed from membrane release devices [ChemTica Internacional (CTI), San José, Costa Rica] emitting $3 \mathrm{mg}$ / $24 \mathrm{hr}$ of each component at $25^{\circ} \mathrm{C}$ under laboratory conditions (Hallett et al., 1993). In experiment 7 (Figure 11, below) mixtures of 2 and 4 were released at a total rate of $3 \mathrm{mg} / 24 \mathrm{hr}$ from membrane release devices (CTI). Chiral isomers were released from glass capillaries $(1 \mathrm{~mm} \mathrm{ID)} \mathrm{cut} 1 \mathrm{~cm}$ above the 
liquid meniscus, and placed in 300- $\mu$ l capped plastic centrifuge tubes with two 4-mm-diameter holes near the top. Each capillary tube released approximately $0.3 \mathrm{mg} / 24 \mathrm{hr}$ of 2 or 4 at $25^{\circ} \mathrm{C}$. Release of stereoisomeric 4 -methyl-5-nonanol at $1.2 \mathrm{mg} / 24 \mathrm{hr}$ was achieved by use of 4 capillary tubes. Host volatiles were released at $20 \mathrm{mg} / 24 \mathrm{hr}$ (at $25^{\circ} \mathrm{C}$ under laboratory conditions) from $10 \mathrm{ml}$ plastic vials. Freshly cut $(20 \mathrm{~cm}$ pieces) sugarcane stalk ( $250 \mathrm{~g}$ per trap) was prepared immediately before placement.

The first trapping experiment (experiment 1) tested attraction of WISW to traps containing sugarcane alone and in combination with either alcohols 1-4, ketones 5-8, or both (1-4 plus 6-9). Experiment 2 tested attraction of male and female WISW to sugarcane, alcohols 1-4, or both combined. Experiment 3 tested attraction of WISW to sugarcane and alcohols 1-4 quaternary or all possible ternary combinations. Experiment 4 tested attraction of WISW to sugarcane and alcohols 1-4 in quaternary or all possible binary combinations. Experiment 5 tested attraction of WISW to alcohols 1-4 in quaternary and all possible binary combinations. Experiment 6 tested attraction of male and female WISW to sugarcane and alcohols 1-4 singly or in quaternary combination. Experiment 7 tested attraction of WISW to $\mathbf{2}$ or 4 alone and in combination at three different ratios. Experiment 8 tested attraction of WISW to $( \pm)-4$ or $(4 S, 5 S)-4$ alone or combine with $( \pm)-2,(4 R)-2$ or $(4 S)$-2. Experiments 9,10 , and 11 tested attraction of WISW to $2: 4(1: 8)$ alone or in combination with sugarcane or with ethyl acetate, ethyl propionate, or ethyl butyrate singly (experiment 9) and in all binary (experiment 10) and ternary combinations (experiment 11 ).

\section{Statistical Analysis}

Assumptions of normality and homogeneity of variance were tested on all data by graphical assessment of log variance vs. log mean and Bartlett's test, respectively (SAS, 1985; Systat Inc., 1992). Data that did not exhibit a normal distribution were transformed by $(x+0.5)^{0.5}$ or $\log (x+1)$ and subjected to analysis of variance (ANOVA) [PROC GLM (SAS, 1985) or MGLH Fully Factorial (Systat Inc., 1992)] with means compared by Bonferonni's or the Waller-Duncan test at $P=0.05$ (SAS, 1985; Systat Inc., 1992). Means presented are untransformed.

RESULTS

\section{Laboratory Analyses}

Gas chromatographic (GC) analysis of volatiles with flame ionization detector (FID) and electroantennographic detector (EAD) revealed eight male-specific compounds (Figure 2). Hydrogenation and reanalysis of weevil volatiles by GC- 


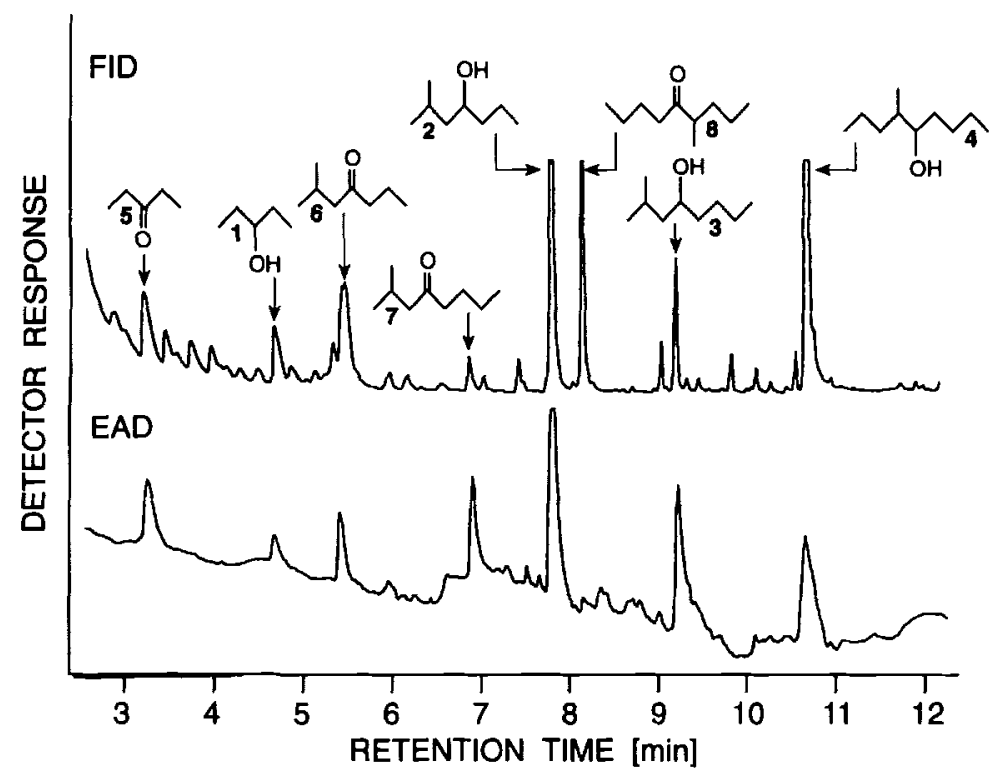

FIG. 2. Flame ionization (FID) and electroantennographic detector (EAD: female WISW antenna) responses to volatiles obtained from unfed male WISW. Chromatography: SP1000 -coated fused silica column; temperature program: $1 \mathrm{~min}$ at $50^{\circ} \mathrm{C}, 10^{\circ} / \mathrm{min}$ to $180^{\circ} \mathrm{C}$. Carrier gas, He; linear flow $35 \mathrm{~cm} / \mathrm{sec}$; injector temperature $250^{\circ} \mathrm{C}$; detector temperature $275^{\circ} \mathrm{C} .1$ = 3-pentanol; 2 = 2-methyl-4-heptanol; 3 = 2-methyl-4-octanol; 4 = 4-methyl-5-nonanol; $5=3$-pentanone; $6=2$-methyl-4-heptanone; $7=2$-methyl4-octanone; $8=4$-methyl-5-nonanone.

EAD revealed antennal responses at the same retention times, indicating all EAD-active compounds contained no $\mathrm{C}-\mathrm{C}$ double or triple bonds. Coupled $\mathrm{GC}$ MS analysis of EAD-active volatiles in both $\mathrm{EI}$ and $\mathrm{CI}$ modes and calculation of their retention indices indicated that the EAD-active compounds were methylbranched ketones and secondary alcohols with molecular weights of 86, 88, $128,130,142,144,156$, and 158. Structures of 1 and 4 (Figure 2) were hypothesized to be 3-pentanol (1) and 4-methyl-5-nonanol (4) based on similarities of their mass spectra with those previously reported (Heller and Milne, 1978; Hallett et al., 1993). Retention indices (RI) of 2 (RI-1310) and 3 (RI1410) on a SP-1000-coated fused silica column suggested they were a saturated analog and homolog, respectively, of (E)-6-methyl-2-hepten-4-ol (9), the aggregation pheromone of Rhynchophorus palmarum, the American palm weevil (APW) (Rochat et al., 1991; Oehlschlager et al., 1992) available in this laboratory. Hydrogenation of synthetic 9 afforded 2 whose retention time coincided with that of WISW-produced 2 on two GC columns (SP-1000 and DB-5). Thus, 
it was hypothesized that 2 and 3 were 2-methyl-4-heptanol and 2-methyl-4octanol, respectively. Identical retention times on two GC columns (SP-1000 and DB-5) and identical mass spectrometric characteristics of authentic alcohols (1-4) and ketones (5-8) with male-produced compounds confirmed structural assignments of all candidate pheromones. Analysis of male-produced 4 on a Cyclodex B fused silica column (Figure 3) revealed that only the $4 S, 5 S$-isomer was present. Since no separation of the enantiomers of 2 was possible on this column, formation of diastereoisomeric derivatives was necessary. GC analysis of the acetyllactate derivatives (Slessor et al., 1985) of male-produced 2 on a DB-1 column revealed that both enantiomers of 2 were present in the weevil extract in a ratio of $4: 6(R: S)$. This finding was confirmed by EI-SIM-MS analyses of the derivatized weevil extract and synthetic $(R)$ - or $(S)-2$.

Semiquantitative analysis of 1-8 in male-produced volatiles revealed the following quantities produced per weevil-hour: $1,2 \mathrm{ng} ; 2,10 \mathrm{ng} ; 3,2 \mathrm{ng} ; 4$,
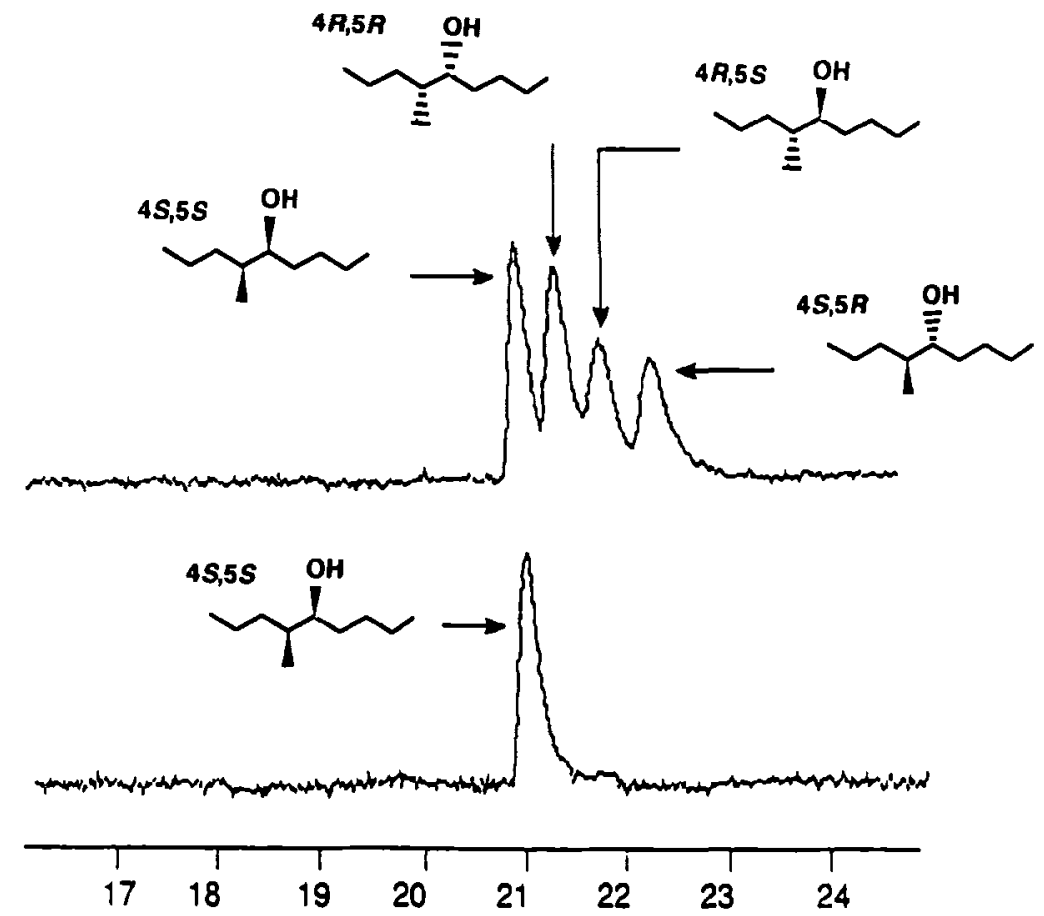

Fig. 3. Selected ion $(m / z=69,87$, and 101) chromatogram (Hewlett-Packard 5985B GC-MS) of (a) synthetic stereoisomeric and (b) weevil-produced 4-methyl-5-nonanol. Chromatography, Cyclodex-B column, isothermal $100^{\circ} \mathrm{C}$; linear flow velocity of carrier gas $35 \mathrm{~cm} / \mathrm{sec}$, split injection and injector temperature $220^{\circ} \mathrm{C}$. 
$40 \mathrm{ng} ; 5,2.2 \mathrm{ng} ; 6,2.1 \mathrm{ng} ; 7,0.7 \mathrm{ng}$; and 8, $4.8 \mathrm{ng}$. Male WISW produce both enantiomers of 2 but only one enantiomer of 4 . Having assumed that male WISW produced one enantiomer of 2 and 4, we employed a 1:8 mixture of racemic 2 and isomeric 4 in our experiments to determine kairomonal synergism. We found no significant difference in the response of WISW to widely varying ratios of 2 and 4 (Figure 11, below). The natural ratio is $1: 16$ of $2: 4$.

GC-EAD analyses of sugarcane volatiles revealed four to seven compounds with antennal responses (Figure 4). Through GC-MS analyses and comparison with authentic standards, the three compounds eliciting the strongest EAD activity were identified as ethyl acetate, ethyl propionate, and ethyl butyrate. Compounds with moderate EAD activity below $2 \mathrm{~min}$ and $\sim 4.5 \mathrm{~min}$ (Figure 4) could not be identified.

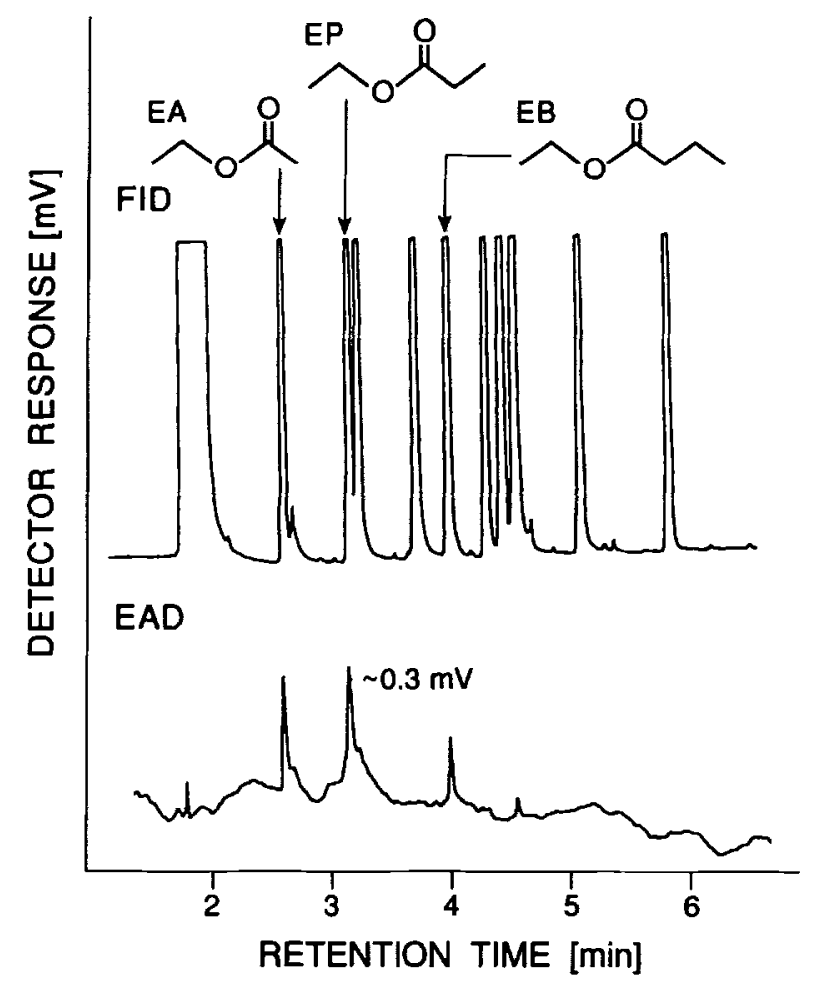

FIG. 4. Flame ionization (FID) and electroanntennographic detector (EAD: female WISW antenna) responses to volatiles obtained from sugarcane. Column and chromatographic conditions as in Figure 2. EA = ethyl acetate; EP = ethyl propionate; EB = ethyl butyrate. 


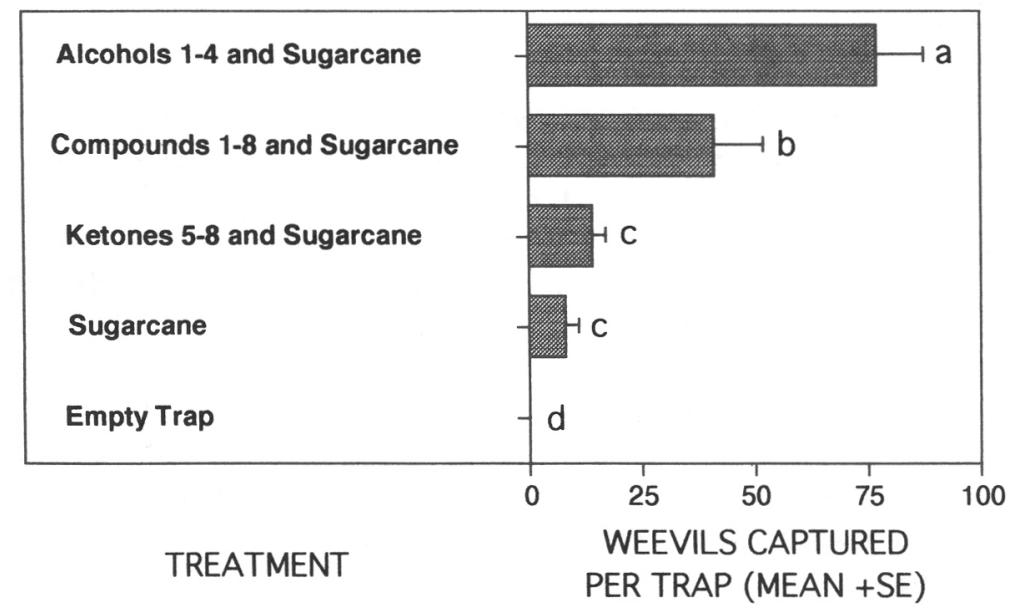

FIG. 5. Mean (+standard error) captures of WISW (experiment 1) in pitfall traps baited with sugarcane $(250 \mathrm{~g})$ alone and in combination with alcohols 1-4, ketones 5-8, and alcohols plus ketones 1-8 vs an empty trap. Alcohols 1-4 and ketones 5-8 were released from devices that emitted $3 \mathrm{mg} / 24 \mathrm{hr}$ at $25^{\circ} \mathrm{C}$ of each component. The experiment $(N$ $=10$ ) was conducted in a banana plantation in Dade County, Florida, March 5-10, 1993. Data [transformed by $(X+0.5)^{0.5}$ to approximate homogeneity] are presented untransformed. Means followed by the same letter are not significantly different according to a Waller-Duncan $k$-ratio $t$ test $(k=100, P<0.05)$.

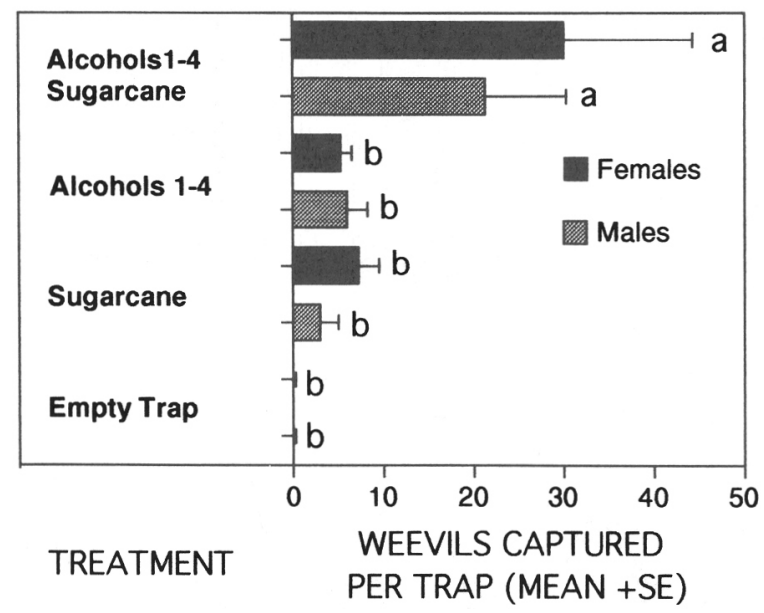

FIG. 6. Mean (+standard error) captures of WISW (experiment 2) in pitfall traps baited with sugarcane or alcohols 1-4 alone and in combination. Alcohols 1-4 were released from devices that emitted $3 \mathrm{mg} / 24 \mathrm{hr}$ at $25^{\circ} \mathrm{C}$ of each component. The experiment $(N$ $=10$ ) was conducted in a banana plantation in Dade County, Florida, March 31-April 5 , 1993. Data [transformed by $(X+0.5)^{0.5}$ to approximate homogeneity] are presented untransformed. Means followed by the same letter are not significantly different according to a Waller-Duncan $k$-ratio $t$ test $(k=100, P<0.05)$. 


\section{Field Experiments}

In field trapping experiments, alcohols 1-4, but not ketones 5-8, enhanced attraction of WISW to sugarcane (experiment 1, Figure 5). The presence of ketones 5-8 reduced attraction of WISW to alcohols 1-4 and sugarcane (Figure 5). Alcohols 1-4, but not ketones 5-8, enhanced attractiveness of sugarcane (experiment 1, Figure 5). Sugarcane and alcohols 1-4 were similarly effective

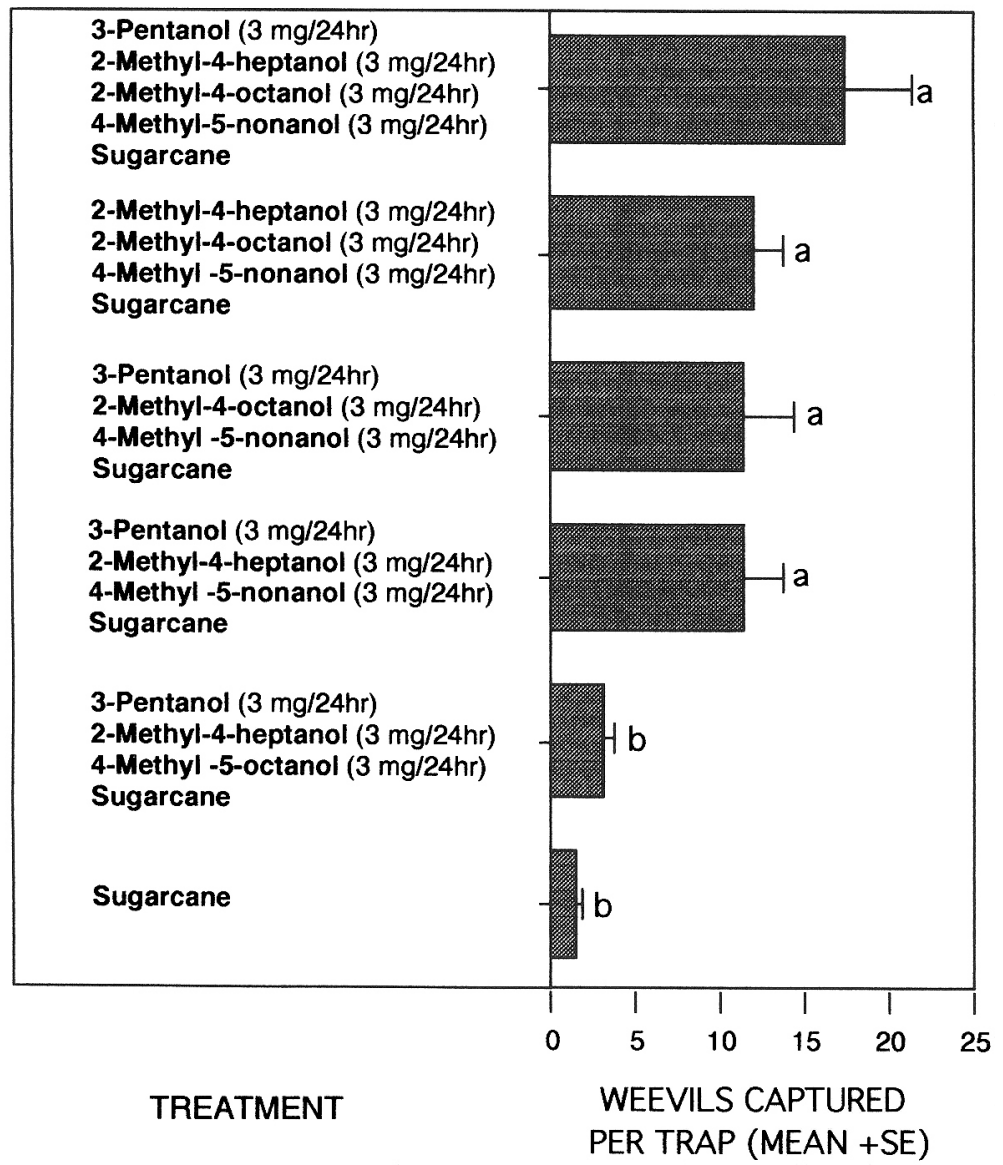

FIG. 7. Mean (+standard error) captures of WISW (experiment 3) in Dipel traps baited with sugarcane alone and in combination with alcohols 1-4 in quaternary and all possible ternary combinations. The experiment $(N=8)$ was conducted in an oil palm plantation surrounding Coto, Costa Rica, September 11-13, 1993. Data [transformed by $(X+$ $0.5)^{0.5}$ to approximate homogeneityl are presented untransformed. ANOVA, $F=12.38$; $d f=5,42 ; P<0.0001$. Means followed by the same letter are not significantly different (Bonferonni's $t$ test, $P<0.05$ ). 
(experiment 2, Figure 6) and equally attracted male and female WISW. In combination with sugarcane, alcohols 1-4 or ternary blends thereof containing 4 were equally effective (experiment 3 , Figure 7 ). Likewise, sugarcane plus alcohols 1-4 or plus binary blends including 4 were equally attractive (experi-

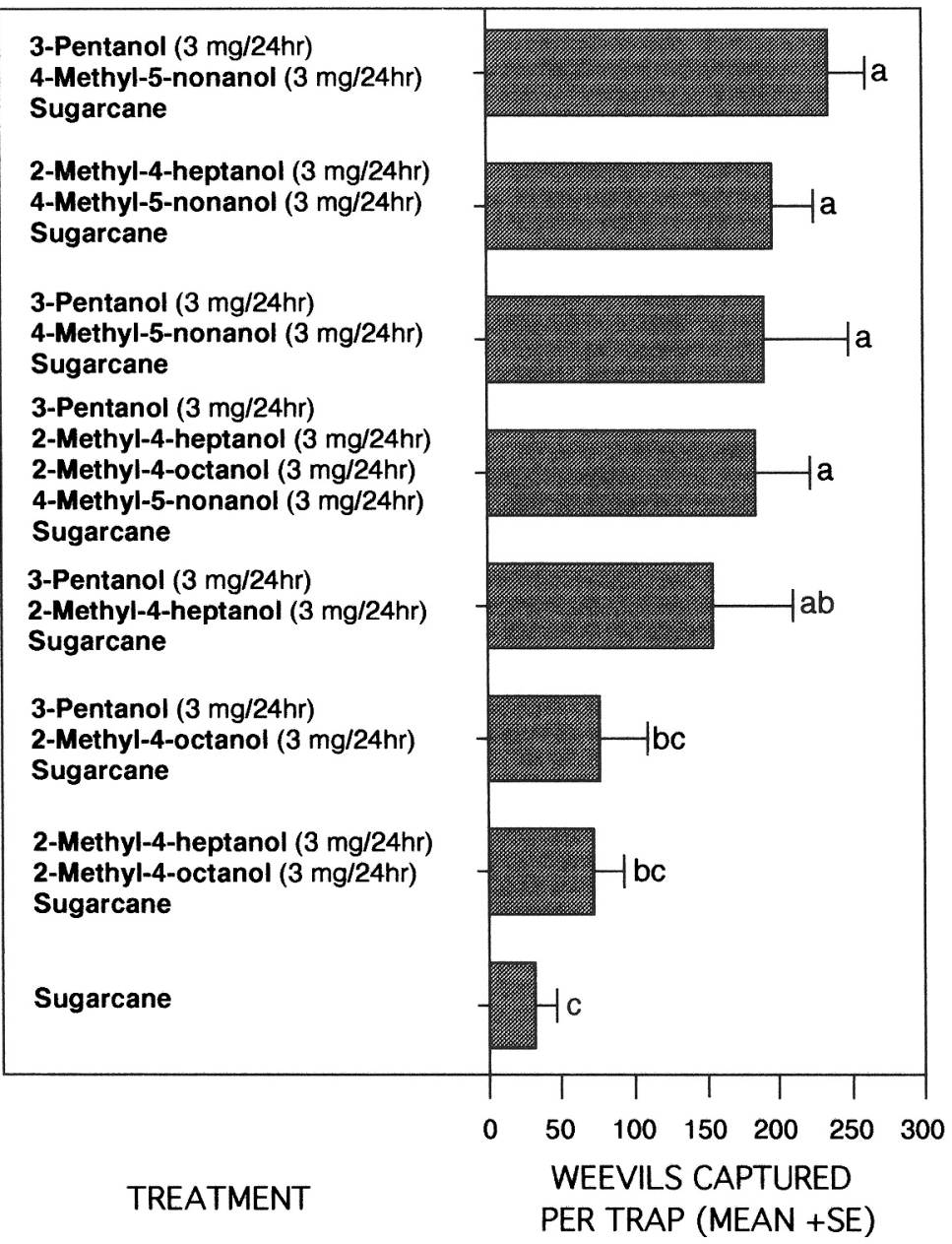

FIG. 8. Mean (+standard error) captures of WISW (expriment 4) in Dipel traps baited with sugarcane alone and in combination with alcohols 1-4 in quatemary and all possible binary combinations. The experiment $(N=6)$ was conducted in an oil palm plantation surrounding Coto, Costa Rica, January 5-8, 1994. Data [transformed by $(X+0.5)^{0.5}$ to approximate homogeneity] are presented untransformed. ANOVA, $F=4.98$; $d f=7$, $40 ; P<0.004$. Means followed by the same letter are not significantly different (Bonferronni's $t$ test, $P<0.05$ ). 
ment 4, Figure 8). Without sugarcane, attractiveness of 2 plus 4 exceeded that of any other binary alcohol blend (experiment 5, Figure 9). Attractiveness of 1,2 , or 3 was significantly lower than of 4 or the quaternary blend of 1-4 (experiment 6, Figure 10). Alcohols 2 plus 4 at each of three ratios attracted more WISW than either component alone (experiment 7, Figure 11). In each treatment of experiment 7 , statistically equivalent numbers of male and female WISW were captured. Experiments 3-7 were repeated a minimum of three times. Invariably, compound 4 was essential for attraction and capture of WISW males and females. Stereoisomeric 4 and $(4 S, 5 S)-4$ were equally attractive and attractiveness of $(4 S, 5 S)-4$ was enhanced by addition of $R-, S$ - or ( \pm )-2 (experiment 8, Figure 12).

Because alcohols 2 plus 4 in experiments 5,7 , and 8 were most attractive, this alcohol blend was chosen to examine possible synergism with EAD-active

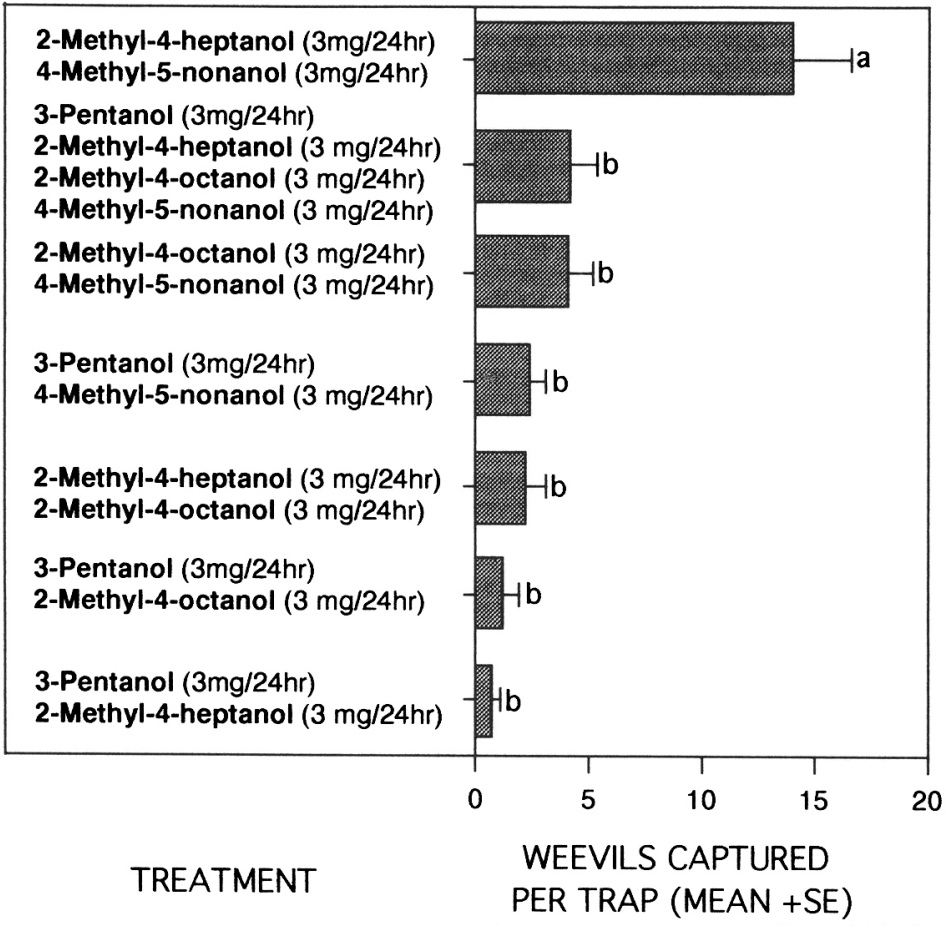

FIG. 9. Mean (+standard error) captures of WISW (experiment 5) in pitfall traps baited with alcohols $1-4$ in quaternary and all possible binary combinations. The experiment $(N=7)$ was conducted in an oil palm plantation surrounding Coto, Costa Rica, November $8-11,1993$. Data [transformed by $(X+0.5)^{0.5}$ to approximate homogeneity] are presented untransformed. ANOVA, $F=10.04 ; d f=6,36 ; P<0.0001$. Means followed by the same letter are not significantly different (Bonferonni's $t$ test, $P<0.05$ ). 


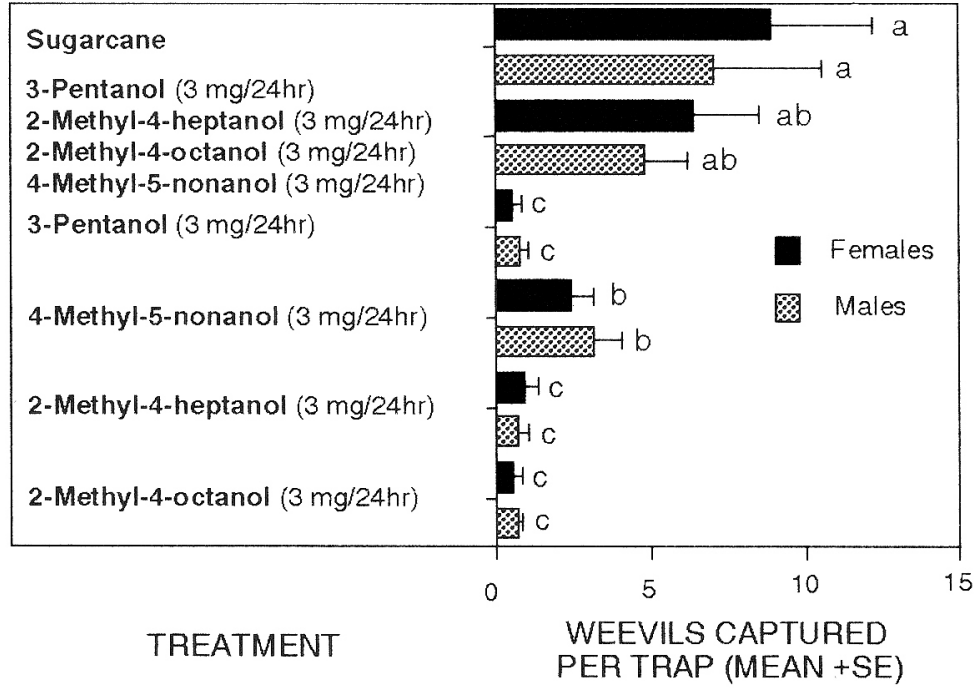

FIG. 10. Mean (+standard error) captures of WISW (experiment 6 ) in pitfall traps baited with alcohols 1-4 singly and in a quatemary blend. The experiment $(N=8)$ was conducted in an oil palm plantation near Rio Claro, Costa Rica, January 12-15, 1994. Data [transformed by $(X+0.5)^{0.5}$ to approximate homogeneity] are presented untransformed. Females: ANOVA, $F=10.52 ; d f=5,35 ; P<0.0001$; males: ANOVA, $F=11.31$; $d f=5,35 ; P<0.0001$. Means followed by the same letter are not significantly different (Bonferonni test, $P<0.05$ ).

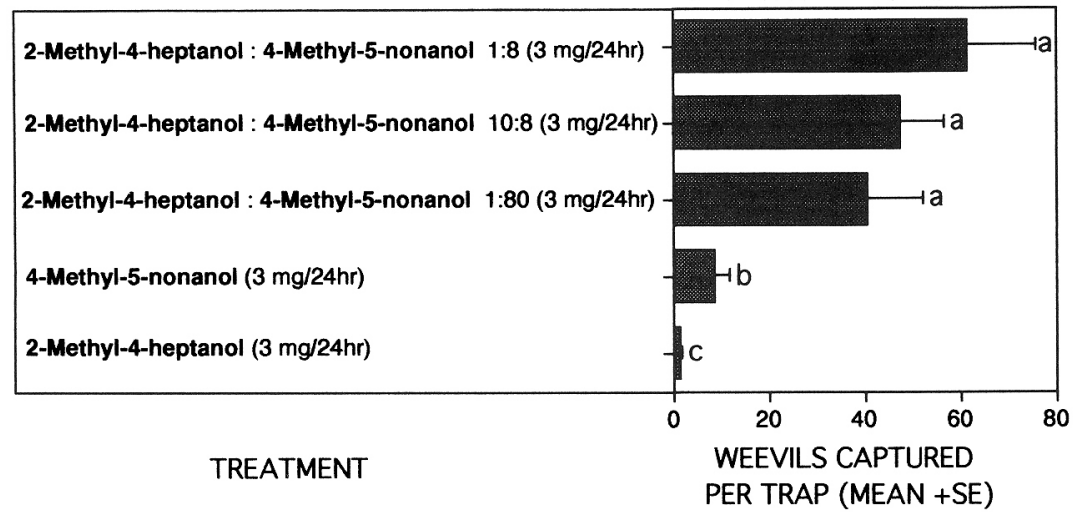

FIG. 11. Mean (+ standard error) captures of WISW (experiment 7) in pitfall traps baited with 2-methyl-4-heptanol and 4-methyl-5-nonanol individually and in three ratios. The experiment $(N=9)$ was conducted in an oil palm plantation surrounding Coto, Costa Rica, November 20-28, 1994. Data [transformed by $\log (X+0.5)$ to approximate homogeneity] are presented untransformed. ANOVA, $F=22.46 ; d f=4,40 ; P<$ $0.000 \mathrm{I}$. Means followed by the same letter are not significantly different (Bonferonni's $t$ test, $P<0.05$ ). 


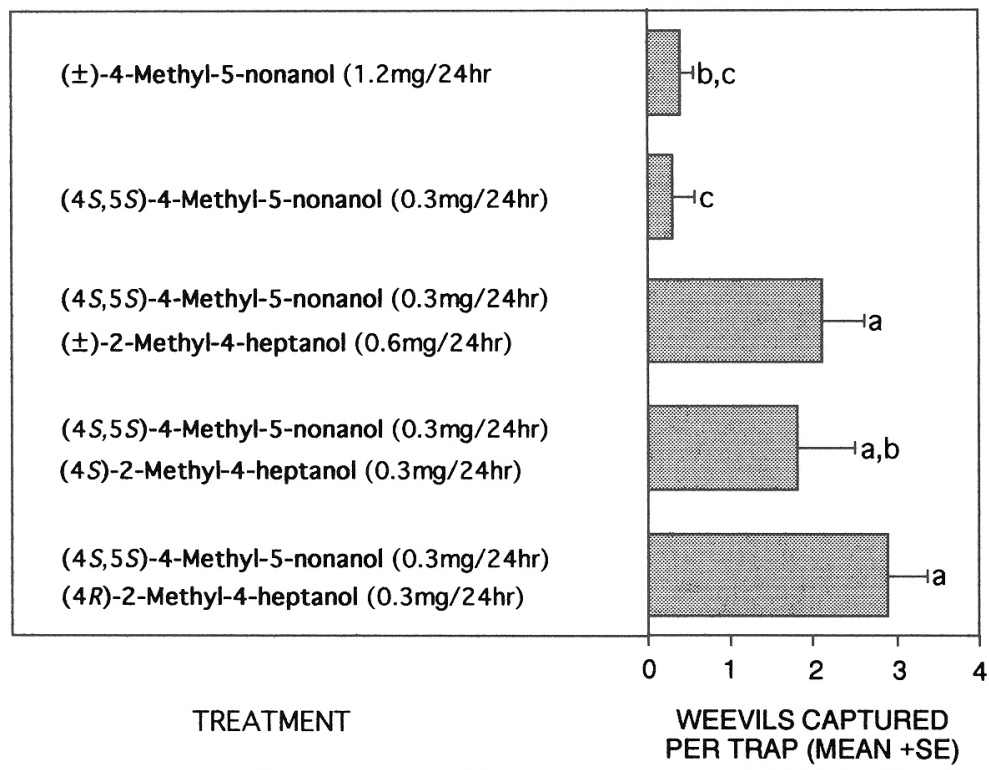

FIG. 12. Mean (+standard error) captures of WISW (experiment 8 ) in pitfall traps baited with stereoisomeric 4-methyl-5-nonanol (4) and (4S,5S)-4 alone and combined with racemic 2-methyl-4-heptanol (2), S-2 or $R$-2. The experiment $(N=10)$ was conducted in an oil palm plantation surrounding Coto, Costa Rica, August 11-24, 1994. Data [transformed by $\log (X+0.5)$ to approximate homogeneity] are presented untransformed. ANOVA, $F=7.67 ; d f=4,45 ; P<0.001$. Means followed by the same letter are not significantly different (Bonferonni's $t$ test, $P<0.05$ ).

sugarcane volatiles. Attractiveness of alcohols 2 plus 4 at a ratio of $1: 8$ increased upon addition of ethyl acetate, ethyl propionate or ethyl butyrate singly or in binary or ternary combinations (experiments 9,10 , and 11; Figure 13). Synergistic activity of fresh sugarcane exceeded that of the above esters 10-100 times.

\section{DISCUSSION}

The production of four EAD-active alcohols and corresponding ketones suggested a complex chemical communication system in WISW. While initial field tests revealed that attraction of WISW depended on the presence of EADactive alcohols and not the corresponding ketones, further tests identified 4 as the major pheromonal component (Perez et al., 1995). Although 2 was not attractive by itself, it enhanced attractiveness of 4 and is obviously a second WISW pheromonal component. Superior EAD-activity of 2 rather than 4 is 

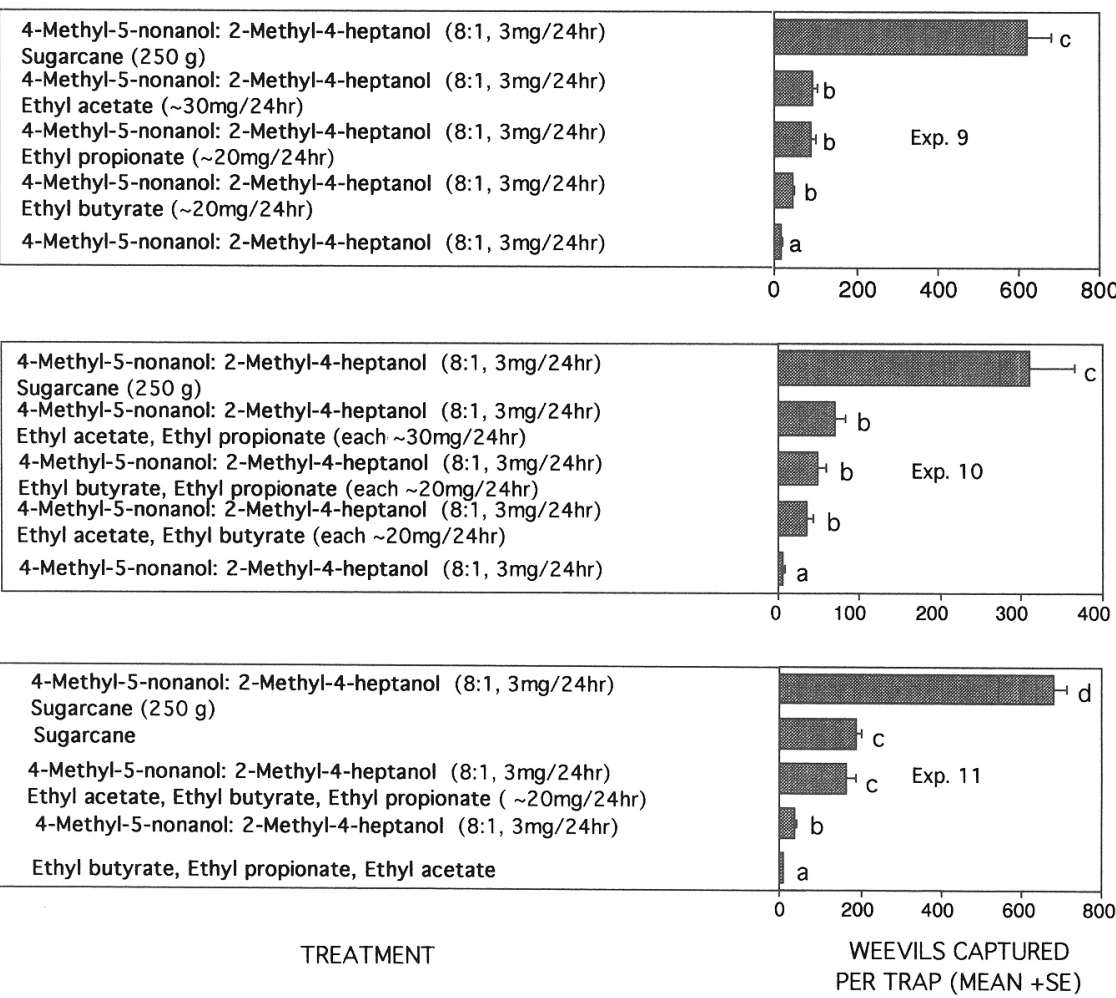

PER TRAP (MEAN +SE)

FIG. 13. Mean (+standard error) captures of WISW (experiments 9-11) in Dipel traps baited with a 1:8 mixture of 2-methyl-4-heptanol (2) and 4-methyl-5-nonanol (4) alone and combined with sugarcane (presoaked in Sevin 80 ) or with ethyl acetate, ethyl propionate, or ethyl butyrate singly (experiment 9) or in binary combination (experiment 10). Experiment 11 tested the blend of ethyl acetate, ethyl propionate, and ethyl butyrate alone and combined with 2 plus 4 vs. sugarcane alone and combined with 2 plus 4 . Treatments without sugarcane used detergent-laced water as the killing agent. All experiments were conducted in an oil palm plantation surrounding Coto, Costa Rica. Data of all experiments were transformed to approximate homogeneity but are presented untransformed. Experiment 9: $N=9$; October 11-21, 1994; data transformed $(X+1)^{0.5}$; ANOVA, $F=13.56 ; d f=4,38 ; P<0.0001$. Experiment $10 ; N=9$; October $21-$ 28, 1994; data transformed by $\log (X+1)$; ANOVA, $F=49.66 ; d f=4,39 ; P<$ 0.0001. Experiment 11: $N=9$; October 29-November 6, 1994; data transformed by ( $X$ $+1)^{0.5}$; ANOVA, $F=176.01 ; d f=4,40 ; P<0.0001$. In each of experiments $9-11$ means followed by the same letter are not significantly different (Bonferonni's $t$ test, $P$ $<0.05$ ). 
surprising but may be attributed to the fact that 2 constitutes both a second WISW pheromonal component and a component of sympatric Paramasius distortus (Gemminger \& Harold) [= Metamasius inaequalis (Gyllenhal); Perez et al., unpublished)]. Because blends of 2 plus 4 attracted both male and female WISW, they are an aggregation rather than a sex pheromone. A recent report suggests that a 1: 10 ratio of 3 to 4 is as attractive as a similar ratio of 2 and 4 when presented with sugarcane; an interesting aspect of that report is that it is claimed that the sex ratio captured depends on the ratio of $3: 4$ or $2: 4$ used (Ramirez-Lucas et al., 1996b). Although male WISW may produce additional components that could add to the attractiveness of 2 plus 4 or 3 plus 4 and sugarcane, the current combination of 2 plus 4 and sugarcane is sufficiently attractive to warrant investigation for monitoring and population reduction through mass trapping. In a separate work we have determined that addition of ethyl acetate to the ternary blend of $\mathbf{2 , 4}$, and sugarcane significantly increases capture rates (Giblin-Davis et al., 1996).

The major aggregation component of the WISW, 4, has been reported as an aggregation pheromone component in several species of Rhynchophorus weevils (Hallett et al., 1993; Oehlschlager et al., 1995; Perez et al., 1996). The presence and EAD activity of 4 in the American palm weevil, $R$. palmarum (Oehlschlager et al., unpublished) and in Dynamis borassi (Fabr.) (Giblin-Davis et al., unpublished) indicate that this compound occurs in at least three genera of tropical curculionids. All tropical Curculionidae investigated to date that use 4 as an aggregation pheronome component employ the $4 S, 5 S$ isomer to attract conspecifics (Hallett et al., 1993; Oehlschlager et al., 1995; Perez et al., 1996). Prior to our initial report of $(4 S, 5 S)-4$ as a pheromonal component of the WISW (Perez et al., 1995), reports by Rochat et al. (1993) revealed 4 as a "pheromonerelated structure" in WISW without establishment of behavioral activity, and Mori et al. (1993) determined the absolute configuration of naturally produced 4. 5-Nonanol and 3-hydroxy-4-methyl-5-nonanone also produced by WISW males were reported to be EAG active (Ramirez-Lucas et al., 1996a), but they did not elicit significant responses in our GC/EAD recordings.

The potential semiochemical role of EAD-active ketones 5-8 is not clear. Released together with EAD-active alcohols, they reduced attraction, suggesting a role as intra- or interspecific "spacing" pheromones. Attraction to alcohol pheromonal components and "antiaggregative" characteristics of the corresponding ketones has been well documented in the Douglas fir beetle, Dendroctonus pseudotsugae (Hopkins) (Rudinsky, 1973) and in the mountain pine beetle $D$. ponderosae (Hopkins) (Ryker and Yandell, 1983). Production of antiaggregative 5-8 may have been artifically induced by aeration of many confined weevils. Ketones 5-8 could also be intermediates in the biosynthesis of 1-4 as has been shown for other Coleoptera (Vanderwel and Oehlschlager, 
1987). They could have been repellent because release rates differed significantly from natural rates.

Although blends of $\mathbf{2}$ plus $\mathbf{4}$ are attractive alone, attractiveness was strongly increased when combined with sugarcane. Antennally active sugarcane volatiles consisting of ethyl acetate, ethyl propionate, and ethyl butyrate exhibited kariomonal synergism in field experiments. However, none of these esters alone or in combination exhibited synergistic attraction equivalent to sugarcane, which suggests the presence of additional, as yet unknown sugarcane kairomones.

The same esters in fermenting tissues of African oil palm, Elaeis guineensis (Jacq.); coconut palm, Cocos nucifera L.; and cabbage palmetto, Sabal palmetto (Walter), also elicited antennal responses by Rhynchophorus weevils (Gries et al., unpublished). However, kairomonal synergism of ethyl butyrate in WISW; ethyl acetate in $R$. cruentatus (Giblin-Davis et al., 1994b), $R$. palmarum (Jaffé et al., 1993), and WISW; and ethyl propionate in $R$. phoenicis (Gries et al., 1994) and WISW did not approximate synergistic activity of host plant activity. Attraction of sugarcane tissue (in the presence of 2 and 4) can be enhanced further by addition of ethyl acetate (Giblin-Davis et al., 1996). Antennal and behavioral activities of the same esters in Metamasius (WISW) and Rhynchophorus weevils indicate cross-generic recognition of the same kairomones in different plant tissues. As yet unknown kairomones in palm and sugarcane may be cross-generic attractants, whose identification may prolong the service life of traps currently used in semiochemical-based management of Rhynchophorus and Metamasius weevils (Oehlschlager et al., 1993).

Because WISW pheromone component 4 is attractive to APW and APW pheromone component 9 is not repellent to WISW, traps can be baited with 2, 4, and 9 plus sugarcane to capture both weevils (Chinchilla et al., 1996). This tactic seems advantageous for lowering the incidence of red ring disease in those areas where both species are considered to vector the red ring nematode, Bursaphelenchus cocophilus (Chinchilla et al., 1996).

Acknowledgments - We thank the Natural Sciences and Engineering Research Council of Canada for support of this research through Research and Infrastructure grants to ACO, the United States Department of Agriculture (USDA) for support through a special grant in Tropical and Subtropical Agriculture CRSR-95-34135-1763 to R.M.G.-D. and J.E.P. and the University of Costa Rica for a fellowship to A.L.P. We thank the technical staff of Palma Tica for invaluable help in field experimentation.

\section{REFERENCES}

Arn, H., Städler, E., and Rauscher, S. 1975. The electroantennographic detector-a selective and sensitive tool in the gas chromatographic analysis of insect pheromones. Z. Naturforsch. $30 \mathrm{c}: 722-725$. 
Calvache, H., Meja, A., and Munoz, J. 1995. Accion de Metamasius hemipterus en la transmission del anillo rojo de la palma aceitera. Palmas 15(4):17-22.

Carballo, V., and ArIas de Lopez, P. 1994. Evaluacion de Beauveria bassiana para el control de Cosmopolites sordidus y Metamasius hemipterus (Coleoptera: Curculionidae) en condiciones de campo. Manejo Integrado de Plagas. Costa Rica 31:22-24.

Chinchilla, C. M., Oehlschlager, A. C., and Bulgarelli, J. 1996. A pheromone based trapping system for Rhynchophorus palmanum and Metamasius hemipterus. A.S.D. Oil Palm Papers (Costa Rica) 12:11-17.

FieSER, L. F., and Fieser, M. 1967. Reagents for Organic Synthesis, Vol. 1. Wiley, New York.

Giblin-Davis, R. M., Peña, J. E., and Duncan, R. E. 1994a. Lethal trap for evaluation of semiochemical mediated attraction of Metamasius hemipterus sericeus (Oliver) (Coleoptera: Curculionidae). Fla. Entomol. 77:247-255

Giblin-Davis, R. M., Weissling, T., J., Oehlschlager, A. C., and Gonzalez, L. M. 1994b. Field response of Rhynchophorus cruentatus to its aggregation pheromone and fermenting plant volatiles. Fla. Entomol. 77:164-177.

Giblin-Davis, R. M., Peña, J. E., Oehlschlager, A. C., and Perez, A. L. 1996. Optimization of semiochemical-based trapping of Metamasius hemipterus sericeus (Oliver) (Coleoptera: Curculionidae). J. Chem. Ecol. 22:1389-1410.

Gries, G., Gries, R., Perez, A. L., Gonzalez, L. M., Pierce, H. D., Jr., Oehlschlagfr, A. C., Rhainds, M., Zebeyou, M., and Kovame, B. 1994. Ethyl propionate: Synergistic kariomone for African palm weevil, Rhynchophorus phoenicis (Coleoptera: Curculionidae). J. Chem. Ecol. 20:889-897.

Hallett, R. H., Gries, G., Gries, R., Borden, J. H., Czyzewska, E., Oehtschl.ager, A. C., Pierce, H. D., JR., ANgerilli, N. D. P., and Rauf, A. 1993. Aggregation pheromones of two Asian palm weevils, Rhynchophorus ferrugineus and $R$. vulneratus. Naturwissenschaften 80:328-331.

Heller, S. R., and Milne, G. W. A. 1978. EPA/NIH Mass Spectral Data Base.

Jaffé, K., Sanchez, P., Cerda, H., Hernandfz, J. V., Jaffé, R. Urdandta, N., Gufrra, G., Martinez, R., and Miras, B. 1993. Chemical ecology of the palm weevil Rhynchophorus palmarum (L.) (Coleoptera: Curculionidae): Attraction to host plants and to a male-produced aggregation pheromone. J. Chem. Ecol. 19:1703-1720.

Mori, K., Kiyota, H., Malosse, C., and Rochat, D. 1993. Synthesis of the enantiomers of syn4-methyl-5-nonanol to determine the absolute configuration of the naturally occurring $(4 S, 5 S)$ isomer isolated as the male-produced pheromone compound of Rhynchophorus vulneratus and Metamasius hemipterus. Liebigs Ann. Chem. 1993:1201-1204.

Oehlschlager, A. C., Pierce, A. M., Pierce, H. D., Jr., and Borden, J. H. 1988. Chemical communication in cucujid grain beetles. J. Chem. Ecol. 14:2071-2098.

Oehlschlager, A. C., Pierce, H. D., Jr., Morgan, B., Wimalaratne, P. D. C., Slessor, K. N., King, G. G. S., Gries, G., Gries, R., Borden, J. H., Jiron, L. F., Chinchilla, C. M., and MexzoN, R. 1992. Chirality and field activity of Rhynchopherol, the aggregation pheromone of the American palm weevil. Naturwissenschaften 79:134-135.

Oehlschlager, A. C., Chinchilla, C. M., and Gonzalez, L. M. 1993. Optimization of a pheromone-baited trap for the American palm weevil, Rhynchophorus palmarum. PORIM International Oil Palm Conference, P35, Kuala Lumpur, Malaysia, September.

Oehlschlager, A. C., Prior, R. N. B., Perez, A. L., Gries, R., Gries, G., Pierce, H. D., Jr., and LAUP, S. 1995. Structure, chirality and field activity of an aggregation pheromone for the Asian palm weevil, Rhynchophorus bilineatus (Montr.), (Coleoptera, Curculionidae). J. Chem. Ecol. 21:1619-1629.

Perez, A. L., Gonzalez, L. M., Pierce, H. D., Jr., Oehlschlager, A. C., Campo, Y., Cas trillo, C. G. Chinchilla, C. M., Gries, G., Gries, R., McDonald, R., Giblin-Davis, 
R. M. Peña, J. E., Duncan, R. E., and Andrade, R. 1995. Chemical communication system of the West Indian sugarcane weevil, Metamasius hemipterus. 78th Annual Canadian Society for Chemistry Conference, Guelph, Ontario, May.

Perez, A. L., Hallett, R. H., Gries, R., Gries, G., Oehlschlager, A. C., and Borden, J. H. 1996. Pheromone chirality of the Asian palm weevils, Rhynchophorus ferrugineus (Oliv.) and R. vulneratus (Panz.). J. Chem. Ecol. 22:357-368.

RalGosa, J. 1974. Nuevos disenos de trampas para control de plagas en caña de azúcar (Saccharum officinarum L.). Memorias Congreso de la Sociedada de Entomologia Colombiana, July 7-10, 1974, Cali, Colombia, pp. 5-23.

Ramirez-Lucas, P., Malosse, C., Ducrot, P-H., Lettere, M., and Zagatti, P. 1996a. Chemical identification, electrophysiological and behavioral activities of the pheromone of Metamasius hemipterus (Coleoptera: Curculionidae). Bioorg. Med. Chem. 4:323-330.

Ramirez-lucas, P., Rochat, D., Malosse, C., Zagatti, P., Descoines, C., Mori, K. 1996b. Identification and field activity of the aggregation pheromone of Metamasius hemipterus (Coleoptera: Curculionidae). 13th Annual Meeting of the International Society of Chemical Ecology, Prague, Czech Republic, August.

Rochat, D. C., Malosse, C., Lftterf, M., Ducrot, P.-H., Zagatti, P., Renou, M., and DESCoINs, C. 1991. Male-produced aggregation pheromone of the American palm weevil, Rhynchophorus palmarum L. (Coleoptera: Curculionidae): Collection, identification, electrophysiological activity and laboratory bioassay. J. Chem. Ecol. 17:2127-2141.

Rochat, D. C., Malosse, C., Lettere, M., Ramirez-Lucas, P., Einhorn, J., and Zagatti, P. 1993. Identification of new pheromone-related compounds from volatiles produced by males of four Rhynchophorinae weevils. C.R. Acad. Sci. Paris. Ser. II 316:1737-1742.

Rudinsky, J. A. 1973. Multiple functions of the Douglas fir beetle pheromone 3-methyl-2-cyclohexen-1-one. Environ. Entomol. 2:511-514.

RYKeR, L. C., and YANDELL, K. L. 1983. Effect of vertenone on aggregation of Dendroctonus ponderosae Hopkins (Coleoptera: Scolytidae) to synthetic attractant. Z. Angew. Entomol. 96:452-459.

SAS. 1985. SAS User's guide: Statistics, SAS Institute, Cary, North Carolina.

Slessor, K. N., King, G. G. S., Miller, D. R., Winston, M. L., and CUTFORTh, T. L. 1985. Determination of chirality of alcohol or latent alcohol semiochemicals in individual insects. $J$. Chem. Ecol. 11:1659-1667.

Systat Inc. 1992. Version 5.2. Envanston, Illinois.

Teran, F. O. 1968. The potential use of insecticide-treated cane pieces to attract and control adults of the sugarcane weevil, Metamasius bilobus, in Bolivia. J. Econ. Entomol. 61:1031-1033.

VANDERwel, D. and Oehlschlager A. C. 1987. Biosynthesis and endocrine regulation of pheromone production in Coleoptera, in G. D. Prestwich and G. W. Bloomquist (eds.). Pheromone Biochemistry. Academic Press, New York.

Vaurie, P. 1966. A revision of the Neotropical genus Metamasius (Coleoptera: Curculionidae, Rhynchophorinae). Species groups I and II. Bull. Am. Mus. Nat. Hist. 131:213-337.

WoOdrufF, R. E. and BARANOWSKI, R. M. 1985. Metamasius hemipterus (Linnaeus) recently established in Florida (Coleoptera: Curculionidae). Florida Department of Agiculture and Consumer Services, Division of Plant Industry, Entomology Circular 272, $4 \mathrm{pp}$. 